\title{
Towards a Framework for Integration of User-Centered Design and Agile Methodology
}

\author{
Asma Taslim \\ PMAS Arid Agriculture University, Rawalpindi \\ asma.taslim@yahoo.com
}

\begin{abstract}
Agile practices are release planning, sprint planning, and standup meetings. The Agile provides the requisite time and space for teams, enabling them, to collaborate with each other and build relationship among them. Frequent short meetings are being held daily by Agile teams to identify potential collaboration opportunities to be followed. User Centered Design (UCD) is a user interface design process which lays great emphasis on the usability objectives, user features, environmental circumstances, tasks and work input/flow in the design/model of an interface. However, some challenges occurred when the UCD joins the Agile process such as usability issues, collaboration problems, usability testing etc. The proposed model not only embraces the relevant issues but it resolves the same to a great extent. The evaluation of said model is done through a case study.
\end{abstract}

\section{INTRODUCTION}

The approaches of agile development are lightweight. The process is, however, incremental and iterative. These models are used for various projects having the following characteristics: frequently changing project requirements, small project and short delivery time (Khader .A. 2016). However, the major problems with agile process are that being a programming methodology, it does not commensurate with the understanding of user needs and also not includes designers' interaction and user evaluation. The traditional agile methods have, however, developed with iteration and significant participation of business owners and user representatives, but they do not have usability testing with targeted users. They can determine the instant project from their business point of view that whether it meets their business needs, while actual users in the market may not have an access to understand and use the interface.

It appears that it would be an impossible objective to connect and relate UCD with Agile process. However, now this is a major challenge for the software development industry that how to make a software useful, usable and enhance its usability in a much short time.

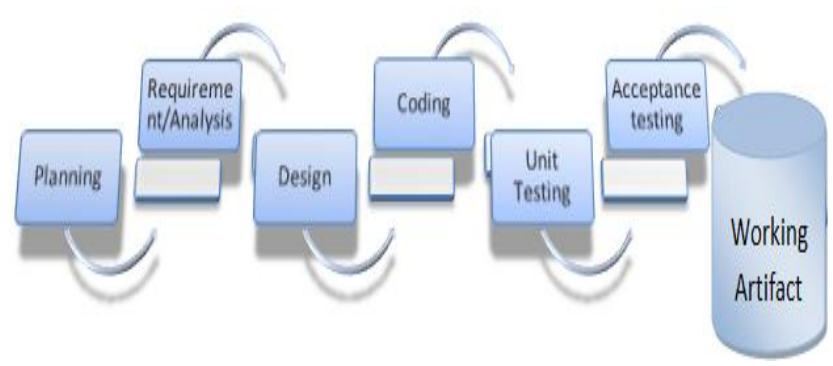

FIGURE 1: Agile Iteration life cycle 
The answer would be thus, to integrate of UCD and Agile methods with each other. However, the integration is a complicated process which requires enough resources as well as time. They are iterative in nature and lays emphasis on coding and software development, whereas UCD lays emphasis on usability through making an interactive interface design for users.

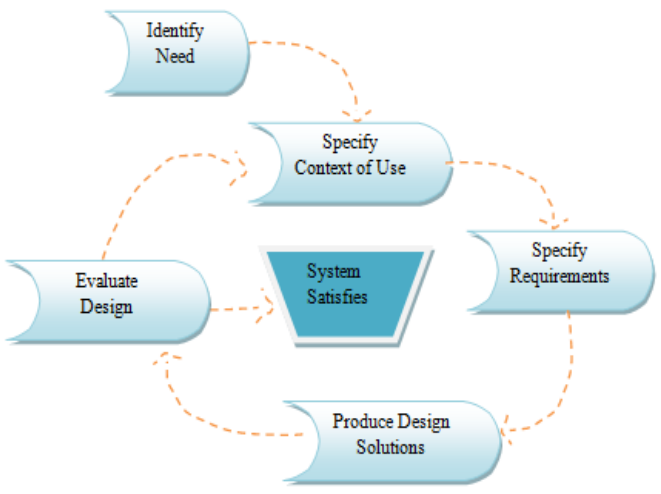

FIGURE 2: UCD Process

Similarly, both of them possess testing methods that are based on an automated code testing whereas the testing in UCD is being done by end user. The significant point is that the agile ignores the usability issues (Masood. S. 2015). Silva. A, (2015) had, however, identified six reasons for the software project failure, i.e. incomplete requirements, lack of user involvement, lack of resources, unrealistic expectations, lack of executive support and changing specifications/requirements. Most of the reasons are caused by communication and interaction issues between developers and stakeholders. However, one reason is that agile methods have recently gained popularity to develop software, due to increased improvements in collaboration between developers and stakeholders, while responding to change of requirements.

UCD needs flexibility to cope with the ground reality when the implementation team encounters the problem(s) that emerges during different design solutions. The only objective is to get the messages by stakeholders across the board and co-locate if possible, because crossdisciplinary collaboration and faced-communications are vital.

Working a sprint, ahead of the development team, helps in allowing the design team enough time to test and iterate. However, a better teamwork creates better software. The roles and responsibilities of agile team highlighted in Fig.3.

The team leader is a facilitator and is responsible for arranging resources, helping and looking after the team. The Product owner shares the concept of the project, prioritizes the functions and takes decisions on behalf of the team or the project. So, he is responsible for the success or failure of the product. The Agile team consists of developers, business analysts, testers, etc. the product owners/ team leader assigns the works/tasks to the entire team accordingly. 


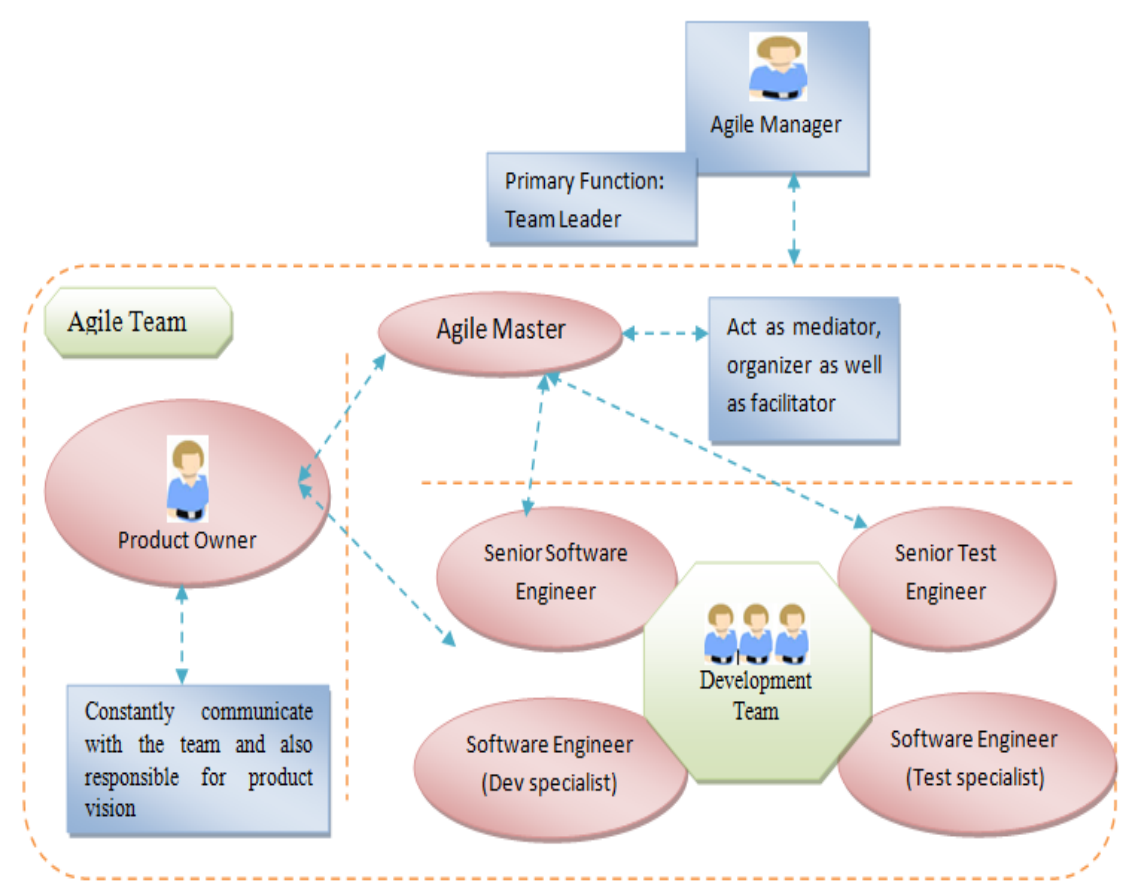

FIGURE 3: Agile Team Structure

\section{REVIEW OF LITERATURE}

Schön. E. et al. (2016), investigates the integration of HCD and agile with Kanban. A design board is introduced and classical user stories have been used instead of persona stories. Results are interpreted because of different experience levels of participants. The participants with poor experience with Kanban are unable to avail all the benefits of HCD activities and results are ambiguous due to the usage of classical stories.

Ethiopia is a developing country facing major challenges of software industry. User stories are in the form of paper sketches or graphs. The project completed but the usability issues like lacking telecommunication infrastructure, lack of prioritization of usability issues and another identified challenge is that several projects are assigned to a single developer (Teka. D.2016).

Gulliksen .J. et al. (2016) indicates that integration of agile development and UCSD has few challenges while producing well tuned product. Studies based on interviews and survey to highlight the issues like time issue for addressing usability. Majority projects are Scrum based which focus on functionality and deliverables instead of quality. Another challenge while using scrum is time management for user activities in the sprint.

Forbrig. P. et al. (2015) discussed two broad approaches HCD and agile development that how to integrate them and highlight the management issue of UCD activities while integrating with Agile process.

Masood. S. et al. (2015) proposed a new agile usability model. Usability issues may resolve before or with software development while highlighting that the usability testing must be the part of the process. The proposed model is cost effective that it helps to recover interface issues before the development of software.

Eileen. M. (2015) gives comparison of UCD agile versus non-agile development process. The overall involvement of user is less in UCD agile processes as compare to non-agile UCD. A key 
challenge addressed is a good communication and collaboration specifically between designers and programmers.

Catarci. T. et al. (2015) proposed a methodology called HORIZAON. It is the integration of three approaches: spiral life cycle model, agile development cycle and UCD. The HORIZON produces a set of tool and technologies within 18 months of the project. But the product is not well tuned while it shows sufficient usability.

Brhel. M. et al. (2015) provided a broad overview of existing knowledge and identify general principles. This literature review highlights the major issues like the prioritization of nonfunctional usability requirements, collaboration issues, and translation of UCASD practices from academia into practices, lack of empirical evidences.

Ardito. C. et al. (2014) reports an experimental study conducted with Software Company. This study confirmed that usability and UX are neglected by most of the companies. The result shows that there is a difference of mindset of developers and programmers. Other challenges addressed are the lack of suitable methods, collaboration issues, neglecting usability and UX in companies' tender notices.

Ait. K. et al. (2014) proposed an Agile-UCD-SOA based framework applied to an earthquake management case study. The three approaches mainly differ in their perspectives. Most important benefit of Agile-UCD-SOA framework is that it leads to highly flexible and agile software should be able to meet rapidly changing business needs. The proposed approach is helpful for complex organization.

Cynthia Y. Lester (2011) combines the principles of UCD with agile manifesto to develop a website. He deduced that using agile and UCD for small projects is easy to implement using XP. The issue highlighted that the hybrid approach is time consuming, become more complex and user skill level decreases.

\section{PROPOSED WORK}

It is revealed from the literature that the main challenges relate to usability, communication and collaboration, time management, etc. Further, the literature points out that usability and end-user play a significant role in producing usable software.

But, the issue is how to produce a usable product. To resolve these issues a framework is proposed in which UCD, is a full partner of Agile team. When the two teams i.e. UCD and Agile merge it will resolve the issue of communication and collaboration. The other benefit of UCD is that it focuses on user's needs so it reduces the stress of Agile team.

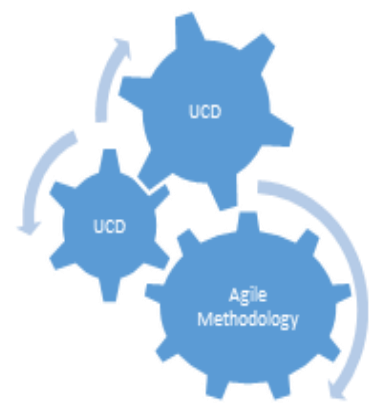

FIGURE 4: Integration of UCD and Agile Methodology

The interaction of UCD with end user is, however, more than in the agile processes which bring a better quality usable product in the market. The work will be streamlined and in timely manner as UCD will be responsible for collaboration and/or meeting arrangements. 
Consequently, timely interactions/ meetings will be done and if change is desired, it will be in early stage.

The other major issue is collaboration among designers and programmers. The UCD designers are responsible for producing clean and clear, organized design files which are updated as new requirements reached. In short meetings they inform or deliver the specific updated design file to programmers as they follow those changes timely. Thus, requirement changes in design enhanced as project is growing. As both designers and developers work together as a well-tuned product is the outcome, which looks like an impossible task without collaboration.

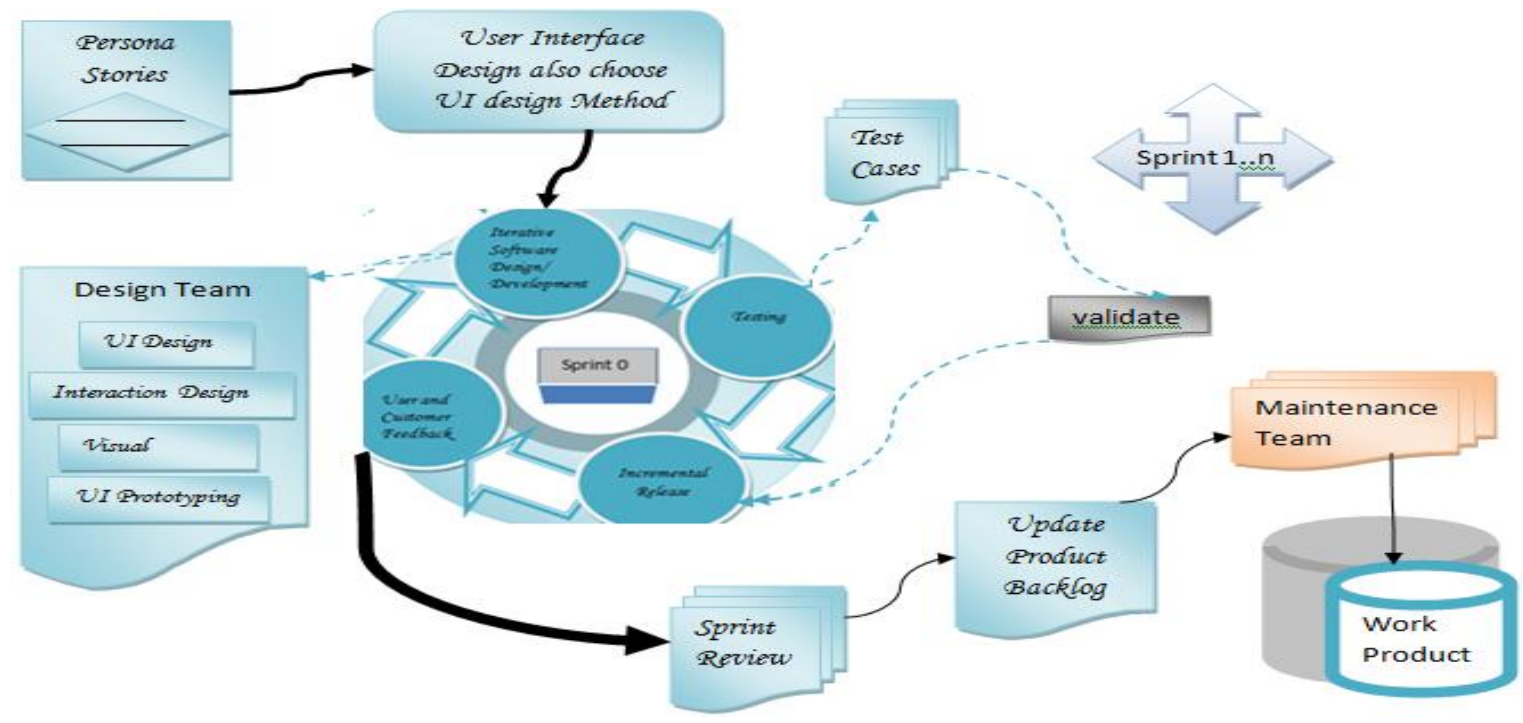

FIGURE 5: Proposed Framework

To integrate agile and UCD practices, to reduce the costs, risks, timing and collaboration issues, etc we structure a framework of combination of UCD and Agile practices which may result in improvement in the usability of working artifact as well as enhancing the activities of Agile development. Users/customers are divided in two groups (Group A and Group B) on the basis of their respective knowledge/information. Group-A indicates users/customers having lesser knowledge about the prevailing software projects. Group-B consists of those clients which have substantial knowledge/understanding about the desired software project and transmit his/her ideas in a better way.

The proposed framework will highlight the following areas: usability issue, time consumption, collaboration issues between designers and developers. Personas have a great potential of attracting/capturing the users/ customers of their requirements. Personas are fictional players with their own characteristics such as name, picture and behaviors/attitudes, etc. Prototypes are using for getting faster feedback and fixing problems before code writing. In smaller projects no need arises to develop prototypes. Only iteration zero is sufficient for designers to develop prototypes and complete the remaining part(s) of design. In large scale projects however the design and development can work at par with each other. On completion of code of earlier prototype, the next one would be given to the developer for development. 


\section{Planning:}

The Planning Phase emphasis on needed project planning. A comprehensive planning of the project is important for a result oriented project. However, a deficient planning/ analysis may lead to project failure. In this phase, the purpose of the project is determined and the production needs are taken into consideration. An estimation of resources/conception of the product is prepared. The following activities are carried out by the designers and developers: assignment scrutiny, scenario, online analysis, persona improvement, individual interactions, contextual interview, focus groups and system usability scale. All the requirements of proposed software product are discussed in a comprehensive meeting with end users.

\section{Design Sprint:}

The sprint in proposed framework is a nine-day answer-question process with customers/end users on designing, prototyping and testing ideas.

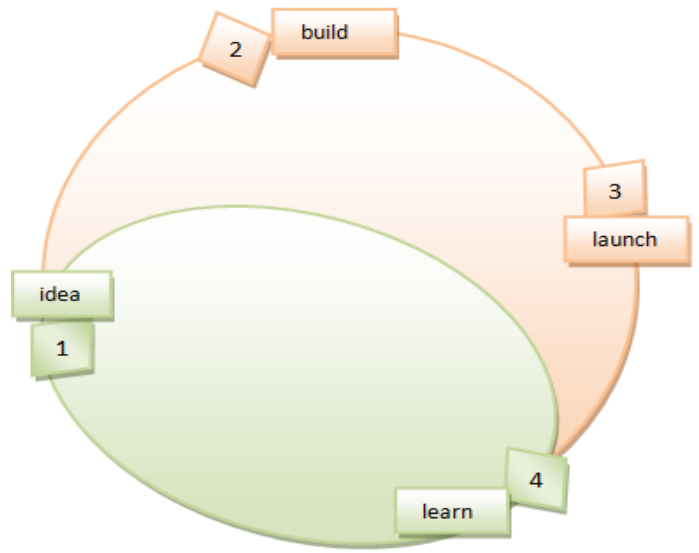

FIGURE 6: Sprint

This process shortens the lengthy deliberation as well as time consumption. To avoid waiting for launching a product, a good idea is ascertained through realistic prototype. The sprint gives us a potential to step in faster in future for a finished goods and customer reaction, which results in saving from expensive/ difficult exercises.

The following artifacts are used in sprint-zero: designing cards, paper prototype and user stories. The designer will carry out the following functions: VI design, Interaction Design and Visual design by using these artifacts, initial design and UI prototype. UI prototyping and architectural prototyping are also involved in it.

The verification process of initial design is essential from the usability side, especially by using practices like first click testing, plan usability testing and recruiting usability testing, running a usability test and reporting a usability test.

\section{Development Sprint $1 \ldots . n$}

After usability testing on need-basis, the interaction designers may redesign and forward it to developers, which are responsible for all functional and non-functional needs. After the user stories are formulated, the development team generates code of low and high fidelity prototype. After receiving feedback from end users, the designers pass on it to the development team for incorporation. In sprint $n$, cards are allocated to describe the problems. Usability is evaluated by using the following: heuristic evaluation, experts review, eye tracking, contextual interview, 
focus groups, remote testing, mobile device testing and scenarios. A description of the proposed framework is given in fig.5. The final outcomes are compared with the desired requirements. After completion of a software development process a performance of complete testing with test cases is initiated and if the client approves the end product, it is given to the maintenance team.

\section{CASE STUDY}

In two organizations, there are two project teams are working separately and an individual observed their work for 3-4 hours per week basis for a period of 6 months. The said organizations have a tradition of employing a user-centered design approach to development. There is a great distinction between designers (responsible for user-centered activities) and developers (generating the code). The observer is a staff member of the organization and is not associated with any of project team. The project teams select/use scrum methodology and their main objective is user/client satisfaction. The case study relates to the dealing of an assortment of scrum, user experience and its practices. The organizations develop software products mainly websites. We, now has classified our case study in two main categories: (a) The team and (b) the software projects.

The team consists of individuals powered to complete the project in the specified time. Further, the design team has 2 designers in organization A and 3 designers in organization $B$. they are worked iteratively for about two months. The development team is highly qualified and experienced in their field of work. The testing team consists of 2 people with three years experience in testing. The remaining team members are shown in Table 1.

\begin{tabular}{|c|l|c|c|}
\hline Sr. No & \multicolumn{1}{|c|}{ Roles } & $\begin{array}{c}\text { Company } \\
\text { A }\end{array}$ & $\begin{array}{c}\text { Company } \\
\text { B }\end{array}$ \\
\hline 1 & Project Manager & 1 & 1 \\
\hline 2 & Product Owner & 1 & 1 \\
\hline 3 & Agile Master & 1 & 1 \\
\hline 4 & Design Team & 3 & 2 \\
\hline 5 & Usability Coach & 1 & 0 \\
\hline 6 & Developers & 2 & 3 \\
\hline 7 & Testers & 2 & (dispersed) \\
\hline 8 & Maintenance Team & 2 & 2 \\
\hline
\end{tabular}

TABLE 1: Team structure

The software projects contain two-type projects in the organizations. One is website development in organization-A and the other is mobile application in organization-B. The design team is working in the organization-A collectedly while in organization-B, the team works as distributor. There are various types of websites such as educational, searching, organizational, photo sharing, writers/authors, blogs, informational, online business, e-commerce and etc. All the websites have their own different features like educational website has much usability aspects such as efficient, perfect and clear. 


\begin{tabular}{|c|c|c|c|}
\hline Sr. No & Roles & Company A & Company B \\
\hline 1 & Project Manager & Lead the team & Lead the team \\
\hline 2 & Product Owner & $\begin{array}{l}\text { Communicate } \\
\text { with team }\end{array}$ & $\begin{array}{l}\text { Communicate } \\
\text { with team }\end{array}$ \\
\hline 3 & Agile Master & $\begin{array}{c}\text { Facilitator for } \\
\text { team }\end{array}$ & Team supporter \\
\hline 4 & Design Team & Design UI & Design UI \\
\hline 5 & Usability Coach & Check usability & Not available \\
\hline 6 & Developers & Code the design & Code the design \\
\hline 7 & Testers & $\begin{array}{l}\text { Test with use } \\
\text { cases }\end{array}$ & Test the project \\
\hline 8 & Maintenance Team & $\begin{array}{l}\text { Maintaining the } \\
\text { project }\end{array}$ & $\begin{array}{l}\text { Maintaining the } \\
\text { project }\end{array}$ \\
\hline
\end{tabular}

TABLE 2: Team roles and their Responsibilities

The features of e-commerce website are such as secure shopping cart, high resolution photos and videos, user generated reviews, etc. The designers play a vital role in the organization-A. They work in an untiring situation as they inspect/examine all the features of the project before handing over to the developers. They keep the prevailing UCD practices in mind while designing the desired project. UCD practices that are using by the organization-A are task analysis, personas, focus groups, usability testing, heuristic evaluation, prototyping, parallel design and wire-framing. However, organization-B uses contextual Interview, usability Testing, Scenarios, prototyping, mobile device testing and card sorting.

By applying the proposed framework to organization-B for a period of three months, the result is better than the previous practice/application. A comparison of both practices is shown in Table 3.

\begin{tabular}{|l|l|l|}
\hline Srde & Factors & $\begin{array}{l}\text { Proposed } \\
\text { Framework }\end{array}$ \\
\hline 1 & User Centric & Yes \\
\hline 2 & Iterative testing & Yes \\
\hline 3 & Collaboration & Yes \\
\hline 4 & Incremental development & Yes \\
\hline 5 & Effectiveness & Yes \\
\hline 6 & Incremental Release & Yes (Frequently) \\
\hline
\end{tabular}

TABLE 3: Results

In this framework, the usability coach plays a leading role such as quick interaction with users of the product and with development team to design as per desire, prototype, prompt usability testing, and quick delivery of user interface designs.

\section{RESULTS}

It is revealed from the above that organization-A has throughout impact of the usability application in the project. The reason is that the designers give great emphasis on the usability. This results in not only reducing communication and collaboration gap/ distance among the designing team and developing team but also time-saving. Further, persona also remains very helpful for the designers in our study. We have used persona instead of user stories in our study 
because persona is efficient, improve software accuracy and further prototypes eliminate the vagueness for the developers. The interaction designers play a vital role for the developers particularly in clarifying the requirements for better understanding of the project. The communication gap between the designers and developers is reduced to a great extent while doing prototyping and testing. However, the same, in organization-B, are difficult for developers and designers at distribution level. The testing of project in organization-A is usability testing/evaluation which is much helpful in planning, conduction/analyzing and also achieves great learning, efficiency and error fixing in early stage. Whereas, actual user testing is troublesome due to lengthy process. For a higher level of usability the project team must be collocated to the extent possible. However, it is a difficult task to deal with distributed team for ensuring high level usability.

\section{CONCLUSION AND FUTURE WORK}

From the fore going, it is concluded that from the integration of UCD and Agile we may achieve a better client satisfaction, usability, reduced communication gap between designers and developers, cost effectiveness, saving in time. By application of the proposed framework we ascertained the desired results. We have applied our framework to both collocated and distributed environment. However, we get a better result from the collocated environment.

\section{REFFERENCES}

[1] Ait. D. Idoughi. and C. Kolski. 2014. "Agile \& user centric SOA based service design Framework applied in disaster management".

[2] Ardito. C. Buono. . D. Caivano. P and M. Francesca. 2014. "Investigating and promoting UX practice in industry: an experimental study. International Journal of HumanComputer Studies".

[3] M. Brhel. H. Meth. A. Maedche. 2015. "Exploring Principles of User-Centered Agile Software Development: A Literature Review. Information and Software Technology" 61, 163-181.

[4] Y. Cynthia. Lester, 2011. "Combining agile methods and user-centered design to create a unique User experience: An empirical inquiry. The Fourth International Conference on Advances in Computer- Human Interactions.

[5] T. Catarci. S. R. Humayoun. S. Kimani. and F. Leotta. 2015. "HORIZON: A Development Methodology for Collaborative Projects".

[6] M. Eileen. T. Thorkildsen. 2015. "Comparing User Centered Practices in Agile Versus non-Agile Development.

[7] E. Weimar, A. Plaat, M. B. Goudbeek, I. J. Visser, and A. Nugroho, 2013. "The influence of teamwork quality on software development team performance".

[8] P. Forbrig . and M. Herczeg. 2015. "Managing the Agile Process of Human-Centered Design and Software Developments".

[9] J. Gulliksen. M. Larusdottir and Å. Cajander. 2016. “A License to Kill - Improving UCSD In Agile Development". 
[10] Khader. 2016. "A Proposed Hybrid Agile Framework Model for Mobile Applications Development”. International Journal of Software Engineering \& Applications (IJSEA), Vol.7, No.2.

[11] S. Masood. S. Masood. 2015. "Usability Evaluation Method for Agile Software Development".

[12] A. Silva. R. Matias and M. Perkusich. 2015. "A Bayesian Network Model to Assess Agile Teams' Teamwork Quality". 29th Brazilian Symposium on Software Engineering.

[13] E. Schon. D. Winter. J. Uhlenbrok and M. J. Escalona, 2016. "Enterprise Experience into the Integration of Human Centered Design and Kanban”.

[14] D. Teka. Y. Dittrich and M. Kifle. 2016. "Usability Challenges in an Ethiopian Software Development Organization". $9^{\text {th }}$ International Workshop on Cooperative and Human Aspects of Software Engineering.

[15] K. Werder 2016. "Team Agility and Team Performance - The Moderating Effect of User Involvement". 